\title{
Management of ingested foreign bodies
}

\author{
Jennifer J Telford MD
}

$\mathrm{T}$ he majority of foreign bodies are ingested. Up to $90 \%$ of these will pass through the gastrointestinal tract spontaneously, $10 \%$ to $20 \%$ require endoscopic management and approximately $1 \%$ require surgical management (1). The pediatric population is most at risk, accounting for $80 \%$ of ingested foreign bodies. Adults, especially the mentally impaired, alcoholic and edentulous, may also accidentally ingest a foreign body. Prisoners and psychiatric patients may ingest foreign bodies intentionally for secondary gain, for instance, to instigate transfer to hospital from a prison or psychiatric institution. Purposeful ingestion of foreign bodies for the purpose of drug trafficking also occurs. Ingestion of multiple foreign bodies should always be considered in both children and adults.

Among children and mentally impaired adults, commonly ingested objects include coins, small toys, crayons and batteries. In adults, the most common foreign body ingested is a poorly chewed bolus of meat, a bone or dentures. Intentional ingestion of a foreign body by a prisoner or psychiatric patient is often a razor blade or other sharp metallic object.

The diagnosis is apparent from the patient's history. The patient will often report a sudden onset of dysphagia during a meal, which may be accompanied by chest pain or odynophagia and an inability to tolerate secretions. In children or adults unable to provide a history, a sudden refusal to eat, drooling or respiratory symptoms such as coughing or wheezing due to aspiration are reasons to suspect foreign body ingestion.

A careful physical examination should be performed to assess for signs of perforation such as subcutaneous emphysema or peritoneal signs. Drooling implies complete esophageal obstruction.

Radiographs of the neck, chest and abdomen will reveal metal objects and steak bones as well as the presence of perforation. Fish bones, chicken bones, toothpicks, plastic and glass are not always visible. Barium should be avoided because it hinders subsequent endoscopic management. Gastrograffin (Bracco Diagnostics Canada Inc) is contraindicated in an obstructed esophagus because it is very hypertonic and, if aspirated, it will cause pulmonary edema. A computed tomography scan of the neck, chest and/or abdomen is indicated if perforation is suspected clinically or by radiographs. Metal detectors have been used in place of radiographs to diagnose coin ingestion in children (2).

The majority of ingested or inserted foreign bodies will pass on their own. Endoscopic removal is indicated if the patient is in distress, the foreign body is impacted or the foreign body poses a danger to the patient. Impaction occurs at physiological narrowings or angulations and strictures. The physiological narrowings are the cricopharyngeus, aortic arch, left main stem bronchus, lower esophageal sphincter, pylorus, ileocecal valve and anus. The duodenal sweep is a physiological angulation. Generally, objects greater than $2 \mathrm{~cm}$ in diameter will not pass through the pylorus or ileocecal valve and objects longer than $5 \mathrm{~cm}$ will not pass by the duodenal sweep. Foreign bodies that pose a risk to the patient include sharp objects and button/disk batteries.

Endoscopic management of foreign bodies is usually performed with conscious sedation. General anesthesia is required for children and uncooperative adults. Airway protection in the form of an endoscopic overtube is necessary anytime a foreign body is extracted through the mouth. The overtube is backloaded onto the endoscope and guided down the shaft of the endoscope once the esophagus has been intubated.

Endoscopic removal is contraindicated if the object is located above the upper esophageal sphincter, there is clinical or radiographic evidence of perforation or the foreign body is a package of cocaine. Objects located proximally to the upper esophageal sphincter should be removed by an otolaryngologist. Cocaine packets generally contain a lethal dose to the patient if ruptured and endoscopy should be avoided.

\section{ENDOSCOPIC ACCESSORIES}

A variety of endoscopic accessories should be available (3). Useful equipment includes rat-tooth and alligator forceps, polypectomy snares, Roth polypectomy retrieval baskets, endoscopic mucosal resection caps, banding caps, through-the-scope dilation balloons and biliary extraction baskets. Before beginning the endoscopy, it is useful to practice grasping an object similar in shape to the foreign body with different accessories (4).

\section{ESOPHAGEAL FOOD BOLUS}

An esophageal food bolus impaction invariably contains chewed meat lodged at an esophageal stricture, web or ring. In complete obstruction, the patient is drooling, unable to manage their own secretions. Complete esophageal obstruction or patient distress is an indication for immediate endoscopic management. Otherwise, endoscopic intervention can be delayed because many food boluses will pass spontaneously, but no longer than $12 \mathrm{~h}$ from presentation because the risk of perforation increases.

The push technique is often successful $(5,6)$ but the endoscopist must evaluate for the presence of bone spicules within the meat bolus. The endoscope should be guided to the right 
side of the meat bolus and gently advanced past the bolus into the stomach. Placing the endoscope to the right of the bolus takes advantage of the anatomy of the gastroesophageal junction, which angulates to the left of the patient. As the impacted bolus is bypassed, the esophagus is assessed for pathology. Often, as the bolus is bypassed and the lower esophageal stricture relaxes to admit the endoscope into the stomach, the bolus will spontaneously drop into the fundus. If this is not the case, the endoscope is withdrawn proximal to the bolus and gentle pressure is applied in a downward and leftward direction from the right side of the bolus.

If the push technique is thought to be unsafe due to the presence of bony spicules, or is unsuccessful, then the bolus will need to be extracted. An overtube should be placed to protect the airway. Usually the entire bolus can be grasped in a polypectomy snare and withdrawn; however, if fragmentation of the meat occurs, it will require piecemeal extraction until the bolus is reduced in size such that it passes into the stomach.

Once the meat bolus has been removed, the esophagus should be examined for injury and a causative stricture, ring or web. Dilation may be performed at this time $(5,6)$ but consideration should be given to the amount of mucosal damage from the impacted bolus and patient retching as well as the support available. Extraction of a meat bolus in the endoscopy unit where trained support staff and equipment are readily available could safely be followed by esophageal dilation. However, many of these procedures are performed at night in the emergency department and, depending on the institution, an endoscopic assistant may not be available. If dilation is not performed, the patient should return electively for endoscopic dilation. Before being discharged, the patient should be counselled regarding chewing meat and, if applicable, denture fitting.

Papain (Adolph's Meat Tenderizer) should not be given to the patient because it will cause enzymatic disruption to the esophageal mucosa and has been associated with perforation and death (7).

\section{SHARP-POINTED OBJECTS}

Ingested sharp-pointed objects have the highest rates of perforation, up to $35 \%(8)$. Chevalier Jackson's axiom states that advancing points puncture, trailing do not (9). Objects leading with the sharp or pointed end, whether during their course through the gastrointestinal tract or during endoscopic extraction, are at risk of perforation. Once objects have passed into the small intestine, the mural withdrawal reflex will assist in turning the object such that the sharp end becomes the trailing end (1).

Sharp objects within the esophagus should be removed endoscopically on an urgent basis. An overtube should be employed to protect the airway and the upper esophageal sphincter. Given the risk of perforation, endoscopic removal of sharp objects in the stomach or duodenum should also be attempted. If the object is beyond reach of the endoscope, then it should be followed with daily imaging. Surgical intervention is considered if the patient develops symptoms or if the object fails to progress over $72 \mathrm{~h}$ (1). The ileocecal valve is the most common site of impaction and perforation (10). Once the object enters the colon, it will become encased in stool and generally pass uneventfully.

Open safety pins and other objects with one sharp end and one blunt end should be oriented such that the sharp end is trailing during withdrawal. Given the close confines of the esophagus, this is usually only an option if the object has reached or can be advanced into the stomach. In the esophagus, if the sharp end is proximal, the object can be grasped and pushed into the stomach, then turned, the blunt end grasped and the object withdrawn.

If the object does not have a blunt end to lead during extraction, the lower esophageal sphincter needs to be protected. A long overtube may be employed, such as that used in push enteroscopy. Alternatively, a banding or endoscopic mucosal resection cap can be placed on the end of the endoscope. The object can then be grasped and the sharp end withdrawn into the cap. If these accessories are not available, then attaching a piece of rubber glove or urinary catheter onto the end of the endoscope that pulls over the object as the endoscope is withdrawn through the lower esophageal sphincter is also effective.

\section{BUTTON/DISK BATTERIES}

Button batteries are found in watches, hearing aids, calculators and other small electronic devices. Damage occurs due to pressure, electrical discharge and chemical injury. If both poles of the battery come into contact with the mucosa, electricity conduction will result in corrosive injury, necrosis and perforation. Furthermore, they contain alkaline fluid, sodium or potassium hydroxide, which may leak into the gastrointestinal lumen and cause necrosis. The batteries also contain heavy metals, but in small amounts that are unlikely to result in toxicity. Button batteries are radiopaque and distinguishable from coins by a double-density shadow or halo (1).

Button batteries within the esophagus should be removed on an urgent basis. The narrow lumen of the esophagus allows mucosal contact with both poles of the battery. Perforation and pulmonary or vascular fistula formation may result (11). Once the battery has passed into the stomach, it will usually pass through the gastrointestinal tract uneventfully if it is less than $2 \mathrm{~cm}$ in diameter. Radiographs are recommended every few days (12). Endoscopic management is considered if the battery does not pass from the stomach. Surgical management is considered if the patient becomes symptomatic and the battery has passed beyond the reach of the endoscope.

Extraction of an ingested button battery requires an overtube. Grasping forceps are contraindicated as they may disrupt the battery seal resulting in leakage of alkali into the lumen. Within the esophagus, a through-the-scope dilation balloon can be passed distal to the battery, inflated and the scope withdrawn pulling the balloon and battery out through the overtube. Alternatively, the battery can be pushed into the stomach and retrieved with a Roth net, biliary extraction basket or a polypectomy snare. Use of the Roth basket is the least challenging technically because the metal wires of the polypectomy snare and biliary extraction basket tend to slide over the battery's smooth surface (13).

\section{LONG OBJECTS}

Long objects, including pens, toothbrushes and cutlery, exceed $5 \mathrm{~cm}$ in length and usually become lodged in the duodenal sweep, requiring removal. Removal can generally be accomplished with a polypectomy snare. Administration of intravenous glucagon may facilitate grasping the object. An overtube is required to protect the airway. 


\section{BLUNT OBJECTS}

The most common blunt foreign bodies are coins ingested by children. Blunt objects lodged in the esophagus should be extracted to avoid pressure necrosis with perforation and fistula formation. Approximately $30 \%$ of coins will pass from the esophagus into the stomach within $24 \mathrm{~h}$ (14). If the object has passed into the stomach and is less than $2 \mathrm{~cm}$ in size, it will usually pass through the gastrointestinal tract without difficulty. In Canadian currency, the penny $(1.9 \mathrm{~cm})$ and dime $(1.8 \mathrm{~cm})$ are less than $2 \mathrm{~cm}$ in diameter, while the two dollar coin $(2.7 \mathrm{~cm})$, one dollar coin $(2.5 \mathrm{~cm})$, quarter $(2.3 \mathrm{~cm})$ and nickel $(2.1 \mathrm{~cm})$ are greater.

Rat-tooth or alligator forceps are able to grasp coins easily. For smooth objects, the Roth net is useful (13). If esophageal extraction is unsuccessful, the object should be pushed into the stomach and further extraction attempts made, or, for objects less than $2 \mathrm{~cm}$ in diameter and $5 \mathrm{~cm}$ in length, the object may be left to pass spontaneously. As with other foreign bodies extracted through the mouth, an overtube is necessary to protect the airway.

\section{SUMMARY}

The majority of ingested foreign bodies pass spontaneously; those greater than $2 \mathrm{~cm}$ in diameter or $5 \mathrm{~cm}$ in length are at risk of impaction. The airway must be protected with an overtube if objects are extracted through the mouth. Immediate endoscopic extraction is indicated for patient distress, complete esophageal obstruction, sharp-pointed objects in the esophagus and button batteries in the esophagus.

\section{REFERENCES}

1. Webb WA. Management of foreign bodies of the upper gastrointestinal tract: Update. Gastrointest Endosc 1995;41:39-51.

2. Bassett KE, Schunk JE, Logan L. Localizing ingested coins with a metal detector. Am J Emerg Med 1999;17:338-41.

3. Nelson DB, Bosco JJ, Curtis WD, et al; American Society for Gastrointestinal Endoscopy. ASGE technology status evaluation report. Endoscopic retrieval devices. February 1999. Gastrointest Endosc 1999;50:932-4.

4. Eisen GM, Baron TH, Dominitz JA, et al. Guideline for the management of ingested foreign bodies. Gastrointest Endosc 2002;55:802-6.

5. Vicari JJ, Johanson JF, Frakes JT. Outcomes of acute esophageal food impaction: Success of the push technique. Gastrointest Endosc 2001;53:178-81.

6. Longstreth GF, Longstreth KJ, Yao JF. Esophageal food impaction: Epidemiology and therapy. A retrospective, observational study. Gastrointest Endosc 2001;53:193-8.

7. Holsinger JW, Furson RL, Sealy WC. Esophageal perforation following meat impaction and papain ingestion. JAMA 1968;204:188-9.

8. Vizcarrondo FJ, Brady PG, Nord HJ. Foreign bodies of the upper gastrointestinal tract. Gastrointest Endosc 1983;29:208-10.

9. Jackson CL. Foreign bodies in the esophagus. Am J Surg 1957;93:308-12.

10. Velitchkov NG, Grigorov GI, Losanoff JE, Kjossev KT. Ingested foreign bodies of the gastrointestinal tract: Retrospective analysis of 542 cases. World J Surg 1996;20:1001-5.

11. Samad L, Ali M, Ramzi H. Button battery ingestion: Hazards of esophageal impaction. J Pediatr Surg 1999;34:1527-31.

12. Litovitz T, Schmitz BF. Ingestion of cylindrical and button batteries: An analysis of 2382 cases. Pediatrics 1992;89:747-57.

13. Faigel DO, Stotland BR, Kochman ML, et al. Device choice and experience level in endoscopic foreign object retrieval: An in vivo study. Gastrointest Endosc 1997;45:490-2.

14. Soprano JV, Mandl KD. Four strategies for the management of esophageal coins in children. Pediatrics 2000;105:e5. 


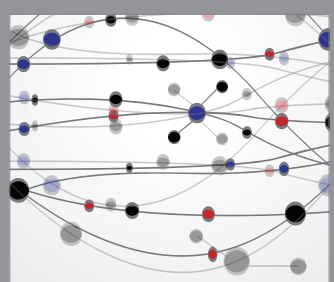

The Scientific World Journal
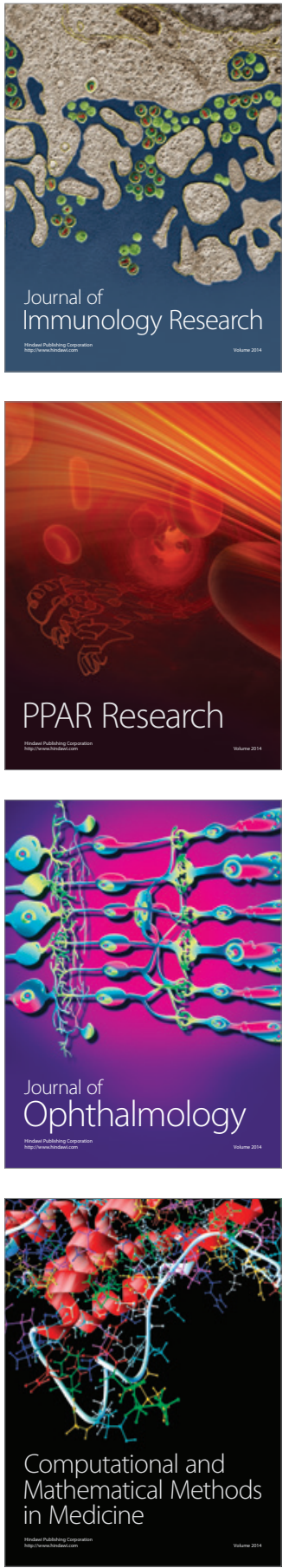

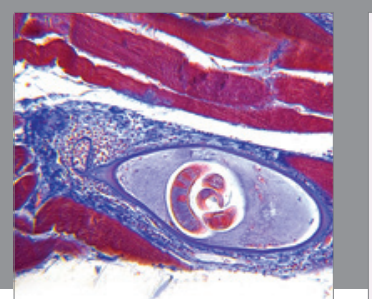

Gastroenterology Research and Practice

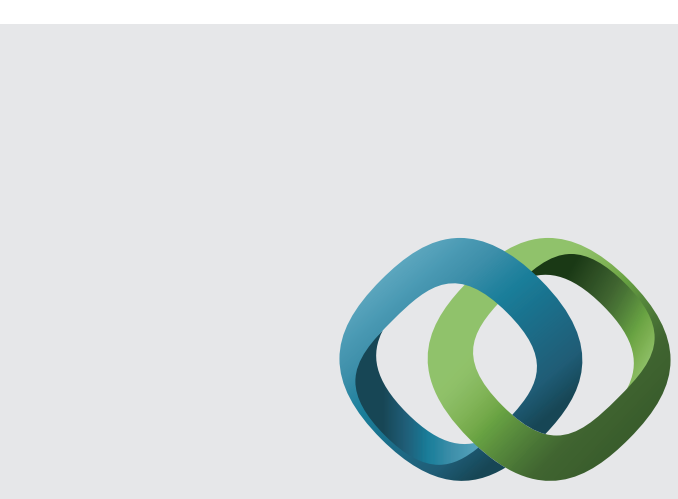

\section{Hindawi}

Submit your manuscripts at

http://www.hindawi.com
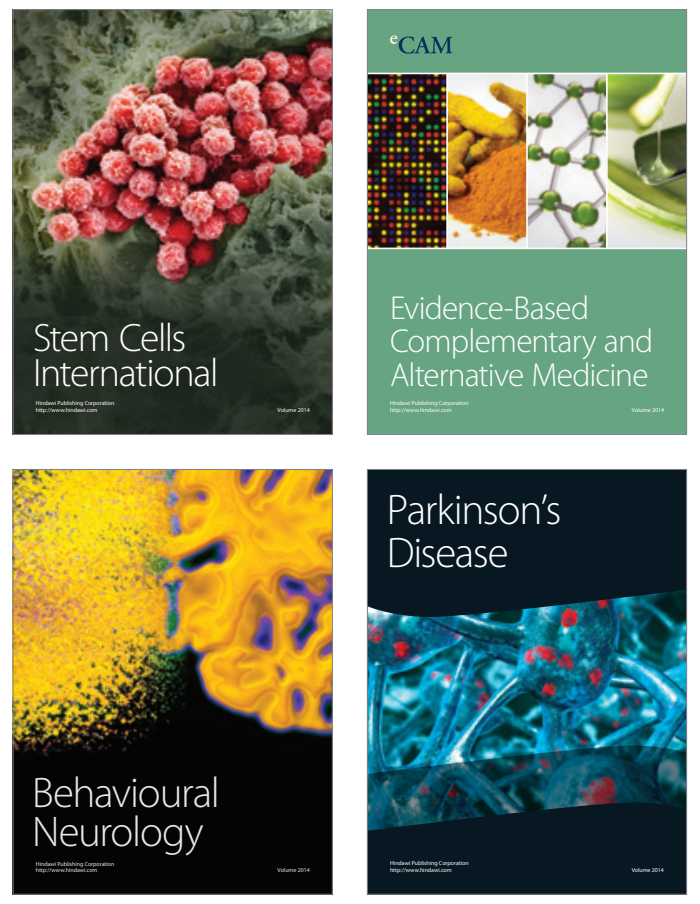
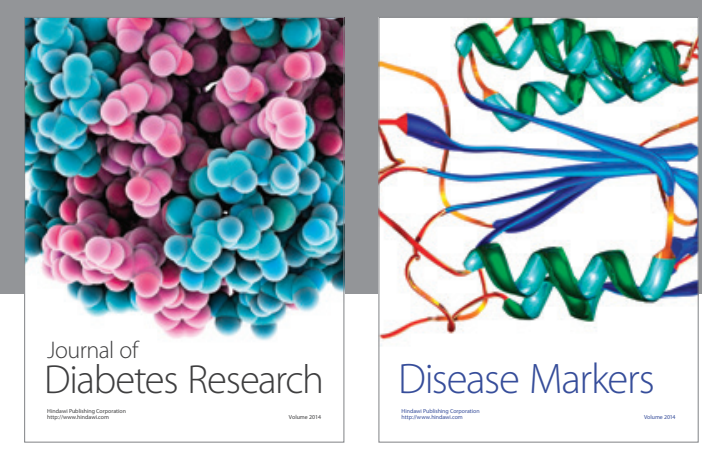

Disease Markers
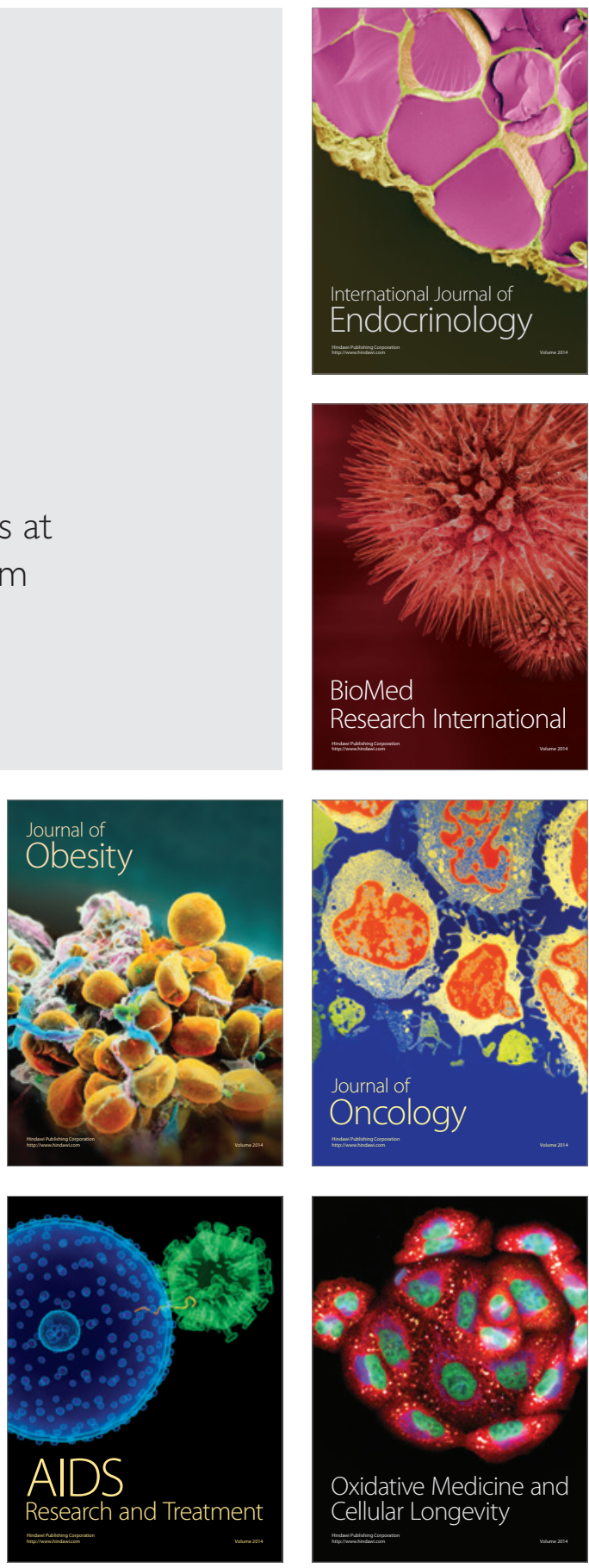